

\title{
TREATING ANIMALS NATURALLY
}

\author{
Peter S. Wenz \\ Sangamon State University
}

Jim Harter, Animals: 1419

Copyright-Free Illustrations.

New York: Dover, 1979



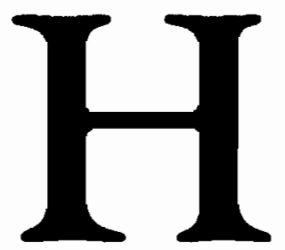

olmes Rolston III's

Environmental Ethics ${ }^{1}$ is a

wide-ranging work

containing many valuable

insights and suggestions. But

his account of the human treatment of animals ${ }^{2}$ is seriously confused. It contains arbitrary distinctions which serve as an apologetic for the status quo in our society. In this paper I explain the problem as Rolston sees it and the solution that Rolston offers. After criticizing Rolston's solution, I propose a significantly different one that rests entirely upon views that Rolston endorses.

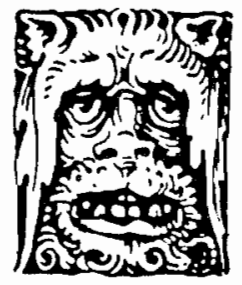

PHILOSOPHY 


\section{The Problem}

Rolston recognizes that an environmental ethic must accept human beings as a part of, not apart from, nature. This means that environmental ethics must prescribe behavior that is natural in the sense that it accords with the place of human beings in the biosphere. But what behaviors are natural to human beings in relation to animals? It is not always clear. For example, people are naturally omnivores. So does living in accordance with nature suggest that we hunt and raise animals for food? People in most climates have a natural (at least occasional) need for warm clothing. Early human beings used animal skins for this and other purposes. So is it natural for people to hunt, trap and raise animals for pelts and leather? People naturally invent tools to help them survive and thrive, so does living in accordance with nature countenance using animals in medical experiments that result in tools (medicines) designed to prolong and/or enhance human life? Grooming is natural to human beings. Does this justify as natural the use of animals in experiments needed to safely (and legally) market new cosmetics? People are naturally curious about animals. Is it, therefore, natural for people to confine exotic animals in zoos to satisfy human curiosity?

\section{Rolston's Account}

Rolston claims that human beings are superior to other animals in having a greater range of interests and possibilities. Only we can read, write and contemplate religious questions. Because there is value in the exercise of these capacities, human life is typically more valuable than the life of any other kind of animal. Even where humans and nonhumans share an interest, as people and elk share an interest in eating, satisfaction of the human's interest should take priority because a well-fed human can realize other values (create poetry or discover mathematical truths) which wellfed elk cannot approach (p. 74).

Rolston does not conclude, as did Kant, that only human beings are worthy of moral consideration. "From superiority we do not move merely to privilege but also to responsibility" (p. 77). Human beings "reflect the highest awareness of values only when they see that humans are not the sole locus of value" (p. 78). Thus, for Rolston, human superiority is reconciled with a basic concern for the well-being of nonhumans by the consideration that part of human superiority is precisely this ability to be concerned about nonhumans.

Concern for animals is naturalistically based, according to Rolston; it rests on natural commonalities between human and nonhuman animals. Many animals can suffer from deprivations of food, water, exercise and social intercourse, just as human beings do. Animals thus have interests similar to the human interest in avoiding such deprivations and suffering. Human superiority is manifested in part by our acceptance of universal benevolence and the Golden Rule as guides for our own behavior. These suggest that, all things being equal, we avoid inflicting harm on animals, and that we relieve their suffering when possible (p. 58). Rolston approves, for example, of a decision requiring a Wyoming rancher to lay down part of his fence so that antelope could migrate in a hard winter to needed foraging lands (pp. 54-55).

Rolston believes, however, that countervailing principles drawn from ecology are often overriding. It is natural for there to be 
predators and prey in an ecosystem. It is also natural for species to evolve through intraspecific competition that leaves many losers as well as winners (p. 56). Much animal suffering, then, makes environmental sense. "This urges a nonmeddlesome Golden Rule and checks benevolence by the realities of ecosystemic nature" (p. 58). Thus, "humans have no duties, in interspecific environmental ethics, to interrupt the course of wild nature" (p. 59). We should express our concern about the suffering of wild animals by not amplifying the cruelty in nature beyond baseline suffering endemic to ecosystemic routines. "So far, this is an ethic of nonaddition but not of subtraction" (p. 60, Rolston's emphasis). "When exploiting nature for human interests," we have no "obligation to reduce ... [animal] suffering below levels found independently of the human presence" (p. 59).

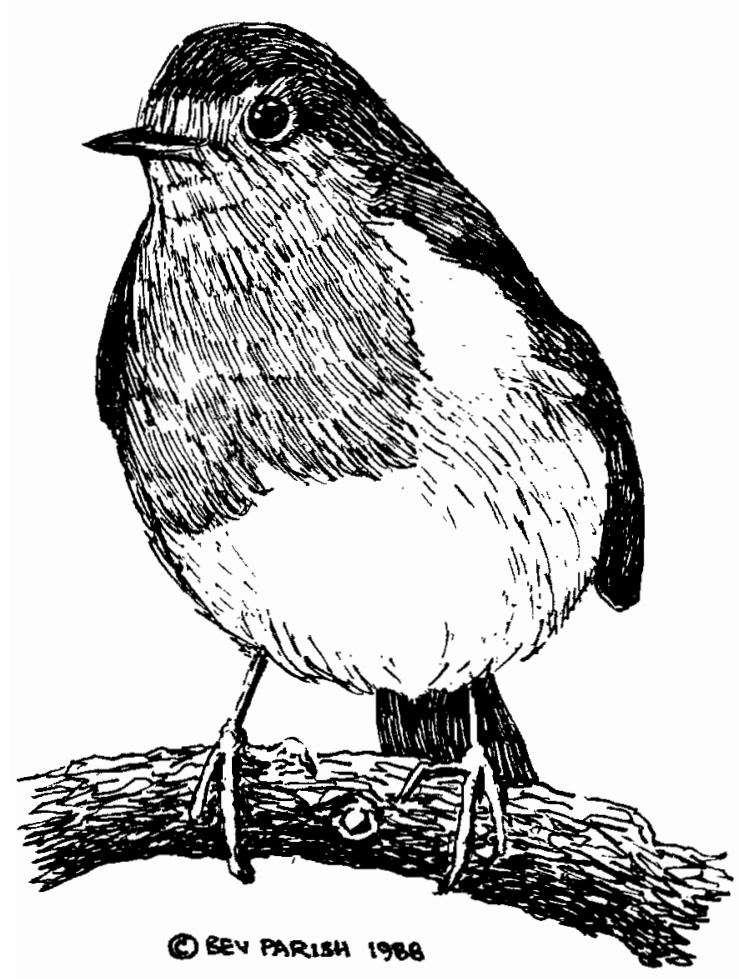

The foregoing reflects two of the three ways in which Rolston would limit the human exploitation of animals. First, because animals have the same interest as we in avoiding suffering, humans should not inflict pointless suffering. Second, humans should not cause animals to suffer "more, on average, than might have been their lot in wild nature" (p. 85).

The third limitation rests on a distinction that Rolston makes among human activities between those based on nature and those based on culture. Because of their superior abilities, human beings live in culture as well as in nature. For example, "marriage, truthtelling, promise-keeping, justice, charity these are not events at all in spontaneous nature" (p. 81). They reflect superior human capacities which are expressed only in culture and which form part of interhuman ethics.

The differences between interhuman ethics and environmental ethics are illustrated by Rolston in reference to interventions designed to prevent suffering. Because animals do not, and cannot, live in culture, we should apply only environmental ethics in our relationships with them. As we have seen, Rolston maintains that environmental ethics should conform to the "realities of ecosystemic nature" (p. 58). Thus, a fawn should not be saved from predation by a grizzly bear. But a human child has a right to be saved. "The human victim has a right only in relation to other humans, with whom it coexists in culture. The grizzly is not violating human rights when it eats a child, but other humans are if they fail to rescue the victim" (p. 57).

Rolston employs the distinction between human activities that are in nature and those that are in culture to frame his third limitation on the human exploitation of animals. 
That exploitation must correspond to natural, rather than to cultural human pursuits. For example, human beings are naturally omnivores. "Hunter-gatherer cultures are the earliest known, and when agricultural cultures replace them, humans have no duty to cease to be omnivores and become herbivores" ( $p$. $80)$. So eating meat is natural, not merely cultural. People are morally permitted to eat meat, then, so long as they inflict no pointless suffering and cause animals to suffer "no more, on average, than might have been their lot in wild nature" (p. 85).

The killing and eating of animals, when they occur in culture, are still events, in nature; ... no matter how superimposed by culture ... Analogous to predation, human consumption of animals is to be judged by the principles of environmental ethics, not those of interhuman ethics. (p. 79)

Rolston extends this logic to other uses of animals. He writes:

There seems no reason to prohibit those uses of animals to provide utilities which, like food, secure health and basic human well-being: leather for shoes, wool for jackets, insulin for diabetics. This stretches the homologous logic beyond that of food chains, but it recognizes that in culture there are necessities unknown in nature. (p. 85)

However, such necessities justify the use of animals only when they are clearly related to natural imperatives, as insulin is related to the maintenance of life itself. Desires which are more purely cultural do not, according to Rolston, justify the use of animals. He objects strongly to trapping and killing wild animals to make fashionable fur coats. However,

Domestic fur bearers, which would not otherwise exist and are humanely treated, are an intermediary case, but even here the fur products are luxuries and cannot be made to fit the ecological model. Using fur and hide for status symbol is something different from using them as survival tools. (p. 85)

On the other hand, Rolston maintains that "a carefully regulated harvest" of alligators in Louisiana is justified, even though the goal is to craft the hides into "ultra chic, terribly expensive purses and shoes," if "the alligator population needs to be cropped for its own good or to prevent its becoming a nuisance" (p. 84). In addition, he suggests acceptability of such uses of alligators around the world on the grounds that "the survival of the alligator may depend on its being economically valuable" (p. 84).

Though Rolston considers acceptable the humane rearing and slaughter of animals for food, he objects to ritual methods of slaughter required by Islamic and Jewish religious traditions because "religious methods of slaughter result in a degree of suffering and distress that does not occur in a properly stunned animal" (p. 83). The additional "pain is ecologically pointless; it has point only culturally and, by the account given here, is not justified" (p. 84).

\section{Critique of Rolston's Account}

I find Rolston's account of our duties regarding animals unconvincing. It rests on a problematic distinction among human activities between those which are natural and those which are cultural. Because it is problematic, the distinction leads to arbitrary and culturally self-serving differentiations among various ways that human beings interact with animals.

The distinction between natural and cul- 
tural human activities is problematic because all human activities are cultural. Hominids evolved culture and then evolved culturally as they evolved biologically. So there never was a natural, noncultural human being or human pursuit. It is natural, and inevitable, for all human activities to be culturally influenced. This renders impossible the task which Rolston sets himself of differentiating among human activities those which are cultural from those which are natural. Yet it is largely such differentiation that Rolston employs to determine our duties regarding animals. All other things being equal, animals can be used in natural pursuits, but not in cultural ones.

\section{A ost people in the I United States condone hunting for meat while abhorring bullfights,} conveniently ignoring the fact that in modern cultures both are recreations, neither is necessary, and the animals involved are harmed equally.

\section{Because the basic distinction between} natural and cultural activities is problematic, Rolston's conclusions about what is acceptable and unacceptable appear arbitrary. As we have seen, animals can be used for leather for shoes but not for fur coats (p. 85). But what is the difference? The human need for shoes is no more natural than the human need for coats. Modern people who can obtain substitutes for the fur in coats can equally obtain substitutes for the leather in shoes. Why, then, is one use impermissible culturally and the other permissible naturally?

A similar arbitrariness characterizes Rolston's distinction between humanely raising animals for food, which is acceptable naturally, and humanely raising animals for fur, which Rolston considers "an intermediary case" (p. 85), that is, not obviously acceptable. But how do the cases differ? Clothing and food are equally natural needs, and animals are no more harmed in humane husbandry for fur than for meat.

Rolston declares unacceptable culturally the use of fur and hides for luxuries and status symbols (p. 85). Yet he condones hunting alligators for hides that will be made into "ultra chic, terribly expensive purses and shoes" (p. 84), if "the alligator population needs to be cropped for its own good" (p. 84). But carnivorous species, such as alligators, unlike herbivores such as deer, do not cause environmental damage through overpopulation, because food supplies naturally limit population increases. ${ }^{3}$ Again, Rolston appears to be making a distinction that corresponds to no real difference. Some luxury products are condemned while for no environmentally sound reason others are condoned.

Another reason Rolston gives for condoning the alligator hunt is that "seventeen of twenty-one crocodilian species worldwide are endangered ... and some think they can be saved only if it can be made economically advantageous to native peoples to keep them" (pp. 84-85). This may, indeed, be a good strategy to save endangered species, but it is hard to reconcile with Rolston's view that only natural, rather than cultural, human needs 
justify harming animals. To the extent that any content can be given to the natural/cultural distinction, one would think that the kinds of economic considerations alluded to would be on the cultural side. Thus, they would not render permissible the otherwise impermissible hunting of alligators for hides for high fashion apparel and accessories. In fact, two pages later Rolston himself writes, "We want our ethical attitudes toward animal suffering to be consistent with ecology, not distorted by economics" (p. 86).

Also puzzling are Rolston's views about the relationship between religion and our treatment of animals. As we have seen, Kosher slaughter is condemned as impermissibly causing extra, unnecessary pain to animals. The extra pain is unnecessary because it is inflicted for purely religious, i.e. cultural, reasons. But then Rolston refers approvingly to the view, associated with Ortega y Gasset, that "hunting is not sport; it is a sacrament of the fundamental, mandatory seeking and taking possession of value that characterizes an ecosystem and from which no culture ever escapes" (p. 91, Rolston's emphasis). Sacraments are associated with religion no less than are Kosher laws. So why is Kosher slaughter impermissible whereas hunting is permissible? Hunting is referred to as a sacrament connected with ecosystemic laws from which no culture ever escapes. But the ecosystemic laws are inescapable, not hunting as a sacrament of those laws.

Rolston himself points out on the same page that cameras can replace guns (just as modern methods of slaughter can replace Kosher methods). So why is not hunting as clearly condemned as Kosher slaughter? Both are particular, cultural ways of relating to the mysteries of life and death. The mysteries are universal, but these two methods of relating to the mysteries are equally culturally particularistic. Neither "sacrament" is more necessary than the other to human existence. Modern people have no more "natural" need for hunting than for Kosher meat. Again, Rolston makes a distinction that seems arbitrary.

Rolston's views about medical experimentation on animals are unclear, as he does not discuss the topic directly. But his statements on related matters seem to have opposite implications concerning medical experiments that cause considerable distress to animals. On the one hand, he considers it natural and permissible for diabetics to use animals to get needed insulin. This suggests the permissibility of using animals for other medical needs, including the testing of new drugs and surgical techniques. On the other hand, he says that we should not cause animals to suffer any more than they would in the wild without the presence of human beings. Many sensitive laboratory animals are bred to be used in extremely distressing experiments; such as LD-50 experiments. ${ }^{4}$ In these, a test substance is fed (sometimes force-fed) or injected into animals until half of the experimental animals die. Because this seems harder on the animals than life in the wild, it seems that Rolston would have to condemn much medical experimentation on animals. But such tests are needed for the development of pharmaceutical interventions analogous to the use of insulin. Rolston's views on this are not at all clear.

His views on factory farming should be clear, as such farming typically causes animals more distress than they would experience in the wild away from people. Many farm animals are deprived of free movement throughout their lives. 5 Yet Rolston fails to condemn such farming. Nor does he condemn 
the consumption of meat from such farms. Instead, by mentioning only the permissibility of eating meat which is humanely raised and slaughtered, he gives the false impression that his principles condone eating the meat that one typically finds at the grocery store in the United States.

The combined effect of Rolston's pronouncements, uncertainties, and silences is to echo popular views, replete with inconsistencies and self-serving blindness. Increasingly popular is the view that animals should not be trapped for fur. There is increasing unease about fur products in general, even those obtained from animals reared on farms. But most people have not seen that the same logic applies to the leather in their shoes and the meat on their table. Most people in the United States condone hunting for meat while abhorring bullfights, conveniently ignoring the fact that in modern cultures both are recreations, neither is necessary, and the animals involved are harmed equally. Most people are conveniently ignorant of the suf. fering of animals on factory farms and in medical experiments. Rolston does nothing to disturb such people. Instead, he ignores what most people ignore and tries to find principles to bring consistency to inconsistent, popular views. In short, Rolston's account is conservative in the worst sense. It papers over difficulties in the status quo that a philosopher should be exposing. Through the use of arbitrary distinctions, it assuages consciences that should be disturbed.

\section{Animals and Evolution}

The following is my suggested alternative account of the natural treatment of animals. Its premises are drawn entirely from materials found in Rolston's book, though not all the premises are applied by Rolston to questions concerning the treatment of individual animals. I concur with these premises and have argued for them elsewhere. 6 The point here, however, is that they are Rolston's views and that they lead to a coherent environmental ethic concerning the treatment of animals.

I begin with Rolston's views that human beings are unique in having moral responsibilities and that our responsibility to avoid causing unnecessary harm includes the responsibility to avoid causing animals to suffer or die unnecessarily. I add to these an idea of Rolston's, but one which he fails to associate with the humane treatment of individual animals; it is the idea that the earth's fecundity is valuable. Aldo Leopold wrote, "the trend of evolution is to elaborate and diversify the biota."7 Rolston, correctly, I think, sees value in this and derives a human duty from it.

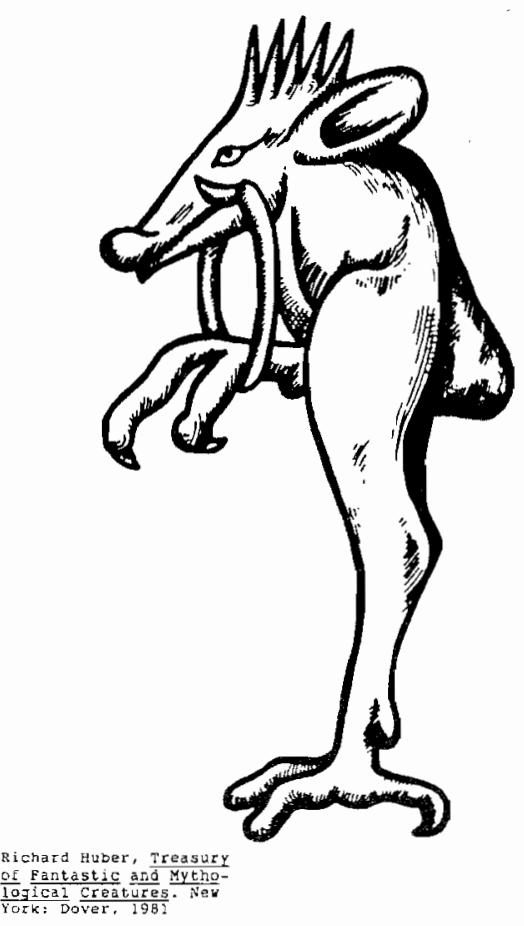


Nature seems to produce as many species as it can, certainly not just enough to stabilize an ecosystem, much less only species that can directly or indirectly serve human needs. Humans ought not to inhibit this exuberant lust for kinds. (p. 157)

Elsewhere he writes, "It is not form (species) as mere morphology, but the formative (speciating) process that humans ought to preserve" (p. 137, Rolston's emphasis).

$\mathbf{P}$ eople should use animals only in ways that do not impair the natural evolutionary process of speciation. People should avoid causing animals to suffer or die, except when doing so is part of the natural, evolutionary process of speciation. People should alleviate animal suffering and prevent animals deaths only when doing so leaves evolutionary processes unimpaired.

I consider this idea to be the key to understanding human duties concerning the suffering and use of animals. ${ }^{8}$ People should use animals only in ways that do not appreciably impair the natural evolutionary process of speciation. People should avoid causing animals to suffer or die, except when doing so is part of the natural, evolutionary process of speciation. People should alleviate animal suffering and prevent animals deaths only when doing so leaves evolutionary processes unimpaired.
These ideas bear significantly on the moral appraisal of practices in some technologically simple cultures. The (traditional) Inuit in Alaska and the !Kyng bushmen in Africa do not interrupt the process of evolutionary speciation; their cultures are compatible with the natural diversification of the biotas on earth. So people in such cultures are not violating duties regarding the biosphere in general when they adhere to their ecologically benign cultural practices. From the perspective of environmental ethics, such people have no duty to reduce the suffering caused to animals by practices which are essential to the maintenance of their culture. Traditional Inuit have no duty to cease hunting seals, and bushmen have no duty to cease hunting porcupines, even though the hunt causes animals to suffer and/or die, because this suffering and death is the minimum necessary to preserve a way of life that preserves the environment.

The reasoning here parallels that concerning the alleviation of the suffering and death of animals in the wild. If wilderness is to be preserved, as I believe it should be (in part because it is the major locus of natural evolutionary change), then people simply cannot intervene so as significantly to ameliorate the suffering and death of wild animals. Such intervention would destroy wilderness areas as wilderness areas. Traditional Inuit and !Kyng cultures are fully part of, not apart from, wilderness environments. Preserving those cultures is as much a part of preserving the wilderness environment as is preserving the presence of a predator species. Thus, viewing people as part of, not apart from their environments, and accepting the continued speciation that takes place in wilderness areas as a good outweighing associated animal suffering and death, yields the view that people should let wilderness areas be. Where people are 
integral to such areas, they should no more be disturbed, or disturb themselves, in response to animal suffering and death than should other environmental constituents be disturbed to ameliorate such suffering or reduce the rate of animal mortality.

On the other hand, the vast majority of human beings live in cultures whose presence tends to reduce biotic diversity. These are agricultural, industrial and post-industrial cultures. People in these cultures cannot claim that the animal suffering and death they cause is necessary for the preservation of wilderness areas and natural speciation. Since an overriding need or good is required to justify causing any being to suffer or die, some other significant consideration(s) will have to be adduced to justify practices in modern cultures that cause animal suffering and death.

For example, innocent people have a right to self-defense and to protection by others when self-defense is not possible. This is based on the idea, elaborated by Rolston (pp. 6275), that the human capacities for morality and other cultural pursuits make individual human beings more valuable than individuals of other species. So when push comes to shove, as in cases of self-defense and the defense of individual human beings from animal attacks, animals should be sacrificed for human welfare. But a technologically sophisticated culture can and should arrange matters so as to minimize attacks by animals, for example, by not breeding and training dogs for fighting and guard duty.

Other examples of permissible animal sacrifice in technologically sophisticated culture are also based on the idea that if human beings are more valuable than any other beings, then it is reasonable that human beings cause animals to suffer and die when this is truly necessary for the preservation of human life. Thus, where no alternatives are feasible, it is legitimate to kill animal pests who threaten human health or vital human food supplies. Similarly, in those relatively rare cases when animal experimentation is required to meet pressing human health needs, medical experimentation on animals is justified. This is not to say, however, that most current practices concerning animal pests and medical experimentation on animals are justified. It is merely to say that, granting greater value to people than to any other of the environment's constituents, one can imagine situations in which some use of animal extermination and experimentation would be justified.

Where vital human needs are not at issue, significant impositions on animals are unjustified, except when needed to reestablish ecological balances that people have upset. Rolston is correct, I believe, when he objects to a rancher's (largely unnecessary) stretch of fencing that blocked antelope from migrating as usual, and as needed, to winter foraging areas (pp. 54-55). But in light of the premises he accepts. Rolston should add considerably to the list of impermissible activities in technologically sophisticated cultures.

People in modern cultures have no real need for products made with fur or leather. Killing animals to provide materials for such products is totally unjustified, even if the animals are raised humanely for this purpose, because killing an animal (obviously) harms it greatly, and thus requires a strong justification. Where there is no real need for products made with leather or fur, there is insufficient justification. A fortiori, painful trapping methods are unjustified.

Hunting and fishing are also unjustified, except when they serve the needs of human subsistence. Since meat is nutritionally super- 
fluous in the human diet, anyone who has alternatives available should avoid killing animals for food.

By the same token, people who have available alternatives, e.g., virtually everyone in the United States, should avoid eating the meat of animals killed by others and should avoid raising animals to be killed for their meat. Even when the animals are raised humanely, killing them is unjustified. A fortiori, factory farming, which causes great animal suffering, is unjustified.

Many species of animals suffer greatly under the conditions of confinement characteristic of most zoos. Human curiosity about these animals is not a need of such magnitude as to justify causing this suffering, especially since books, wildlife photography, and films can meet whatever need exists.

Animal entertainments are fine so long as the animals involved are among those being entertained. It is hard to imagine much joy for the animals in a cockfight or bullfight. I remain skeptical of trainers' and owners' claims that their dogs and horses really enjoy or crave racing as hard as they do. But I have seen dogs fetch sticks with apparent enjoyment. The event did not draw a paying crowd, however.

In sum, people should not cause animals to suffer or die unnecessarily, because suffering and death are harmful. In light of the value of natural speciation in the biosphere, however, people should not intervene in the wild to ameliorate animal suffering. For the same reason, people living in technologically simple cultures (which do not impair natural speciation) have no duty to renounce practices essential to their cultures which cause animals to suffer and die. Because normal human beings are of greater value than are individual animals, innocent people have a right to self- defense and to defense by others in case of animal attack. They are also justified in some extermination of animal pests and in some use of animals in medical experiments. But because people in technologically sophisticated cultures have no need for fur, meat, and leather, all rearing and killing of animals to secure these products is impermissible. Similarly, since people have no need for recreations that harm animals, such as hunting, fishing and horse racing, these recreations are also impermissible. Abiding by these limitations, we fulfill our role as the biosphere's morally responsible members. While our natural superiority gives us the privilege of self-defense, defense of innocent human beings, and rights to limited extermination and experimentation, it denies to us products and pursuits that involve unnecessary suffering and death. This, I believe, is treating animals naturally.

\section{$\underline{\text { Notes }}$}

1 (Philadelphia: Temple University Press, 1988). All references to this work will be made by page number in the text.

2 For convenience I use "animals" throughout for "nonhuman animals."

3 Robert W. Loftin, "The Morality of Hunting," Environmental Ethics Vol. 6, No. 3 (Fall 1984) pp. 244-245.

4 See Peter Singer, Animal Liberation (New York: Avon Books, 1975) p. 48.

5 Singer, pp. 121-128.

${ }^{6}$ See my book Environmental Justice (Albany, N.Y.: SUNY Press, 1988), especially Chapters 7 and 13.

7 Aldo Leopold, A Sand County Almanac (New York: Oxford University Press, 1949, 1969) p. 216

8 It is key to guidance concerning the use of other environmental constituents as well, but that is beyond the scope of the present paper. See Envirommental Justice, pp. 300-309. 